\title{
Risk Factor of Tuberculosis in Children with Nephrotic Syndrome who Received Immunosuppressant Therapy in Hasan Sadikin Hospital
}

\author{
Sitoresmi Prabaningrum* ${ }^{*}$ Diah Asri, Dedi Rachmadi \\ Department of Child Health, Faculty of Medicine, Universitas Padjadjaran/Hasan Sadikin General Hospital, Bandung, Indonesia \\ *Corresponding author: sita0502@yahoo.com
}

Received October 20, 2018; Revised December 28, 2018; Accepted February 03, 2019

\begin{abstract}
Patients with nephrotic syndrome (NS) are in immunocompromised condition due to illness and therapy given. Treatment of NS with long-term steroids, high doses and combination with cyclophosphamide decreases body resistance. Immunocompromised conditions facilitate the occurrence of infection, one of the infections that might occur is tuberculosis (TB) with a high incidence in Indonesia. The aim of the study was to investigate the risk factors of TB in children with NS, specifically related to the duration of steroids administration, and combinations of steroids with cyclophosphamide. This was cross sectional study data retrieval from out-patients and in-patients NS children in RS Hasan Sadikin Bandung (RSHS) during 1st January 2012 until 31st December 2016. Statistical analysis using chi-square test and multiple logistic regression. There were 34 children with TB from 199 NS patients, the prevalence of TB in children with NS in RSHS (17\%). The results showed that duration of steroids administration, combination of steroids and cyclophosphamide, female gender, and under nutrition were significant to tuberculosis incidence ( $\mathrm{p}<0.001$ ). Multiple logistic regression analysis revealed duration of steroid 175,5 days OR 20,7 (CI95\% 7,5-68,1); $\mathrm{p}<0.001$, combination of steroids with cyclophosphamide OR 3,2 (CI95\% 1,1-11,7); $p=0,027$, female gender OR 2,5 (CI95\% 0,9-7,2); $p=0,077$, and under nutrition OR 7,2 (CI95\% 2,4-3,7); $p=0.001$. Duration of steroid administration, combination of steroids with cyclophosphamide, female gender, and under nutrition were risk factors for tuberculosis. The duration of steroid administration was the most dominant factor in the incidence of tuberculosis in children with NS.
\end{abstract}

Keywords: child tuberculosis, immunosuppressant, nephrotic syndrome

Cite This Article: Sitoresmi Prabaningrum, Diah Asri, and Dedi Rachmadi, "Risk Factor of Tuberculosis in Children with Nephrotic Syndrome who Received Immunosuppressant Therapy in Hasan Sadikin Hospital." American Journal of Medical Sciences and Medicine, vol. 7, no. 1 (2019): 6-8. doi: 10.12691/ajmsm-7-1-2.

\section{Introduction}

Nephrotic syndrome (NS) is a kidney disease with a high rate of occurrence in children, ranging from 2 to 7 cases out of 100,000 children aged $<16$ years. [1] In Indonesia, it is reported that about 6 per 100,000 children each year suffer NS. [2] Nephrotic syndrome patients are in immunocompromised conditions caused by the illness and therapy given. Loss of immunoglobulin $\mathrm{G}$ which acts as an antibody to humoral immune system and factor B properdin that contribute to opsonization of bacteria through urine also decline in $\mathrm{T}$ cell function play a role in the occurrence of infection. [3]

Approximately $10-20 \%$ of cases of NS did not respond to steroid treatment and thus require combination of other immunosuppressants. [3] Cyclophosphamide (CPA) is an ankylating agent common used in patient with NS. A study by Latta showed that NS patients with CPA had a higher risk of infection than a single steroid therapy. [4]
In developing countries especially in Indonesia the incidence of TB is very high. [5] Tuberculosis (TB) is an opportunistic infection that might occur in immunocompromised patients as in NS. [6] In immunocompromised conditions the diagnosis of TB becomes more difficult, requiring higher vigilance of the medical personnels. [7] Risk factor of tuberculosis were aged under 5 years, immunocompromised condition, malnutrition, gender males, contact with tb adult. [8]

A study by Tambunan (2001) at Cipto Mangunkusumo Hospital (RSCM) found that the prevalence of TB in children with NS was $15 \%$, two thirds of them aged 10-16 years, and $86.7 \%$ were with under nutrition. [9] Gulati study showed that the prevalence of TB was related to the type of NS, in NS that requiring high steroid doses and other immunosuppressant therapies the prevalence of $\mathrm{TB}$ was higher than in those with lower steroids. [10]

The purpose of this study was to investigate simultaneously risk factor of tuberculosis in nephrotic syndrome patient. 


\section{Material and Methods}

This was cross sectional study, to determine the risk factor of TB in children NS patients. Data were collected retrospectively from NS children's medical records from January 1, 2012 until December 31, 2016 at RSHS Bandung, West Java, Indonesia.

The study inclusion criteria were inpatients and outpatients in RSHS aged 1-14 years, diagnosed with NS according to ISKDC criteria, received steroid therapy or steroid combination therapy with CPA. Exclusion criteria were immunocompromised conditions such as severe malnutrition, diabetes mellitus, patient with Human Immunodeficiency Virus (HIV), malignancy, other autoimmune diseases, incomplete medical records, patients diagnosed with TB prior to steroid and cyclophosphamide therapy. The study forms were filled by the authors based on secondary data from the medical record.

Nutritional status is divided into 2 categories based on the WHO standart growth chart. Under nutrition defined as weight per age -3SD until -2SD and well nutrition defined as weight per age $-2 \mathrm{SD}$ until $+2 \mathrm{SD}$.

\subsection{Statistical Analysis}

Data were presented as percentage or as mean values with standard deviations (mean $\pm \mathrm{SD}$ ). Statistical analysis used multivariate logistic regression to find the most influential factor. Duration of steroid administration, combination of steroids and cyclophosphamide, gender, age of onset NS, and nutritional status were contributing factors measure on this study. All contributing factors are analysis on bivariate statistical analysis then factors with $\mathrm{p}<0,25$ are measured to stepwise multivariate logistic regression. $\mathrm{P}$ value $<0,05$ was considered to be statistically significant.

\section{Results}

From the data on NS patient's medical record for 5 years, there were 34 TB patients from 199 NS patients who met the inclusion criteria.

Table 1. Risk Factor of Tuberculosis in Nephrotic Syndrome Patient

\begin{tabular}{|c|c|c|c|}
\hline \multirow[b]{2}{*}{ Variable } & \multicolumn{2}{|c|}{ Group } & \multirow[b]{2}{*}{$P$ value } \\
\hline & $\begin{array}{c}\mathrm{Tb} \\
\mathrm{n}(\%)\end{array}$ & $\begin{array}{c}\text { Non Tb } \\
\mathrm{n}(\%)\end{array}$ & \\
\hline \multicolumn{4}{|l|}{ Duration of steroid (days) } \\
\hline Mean \pm SD & $175.5 \pm 90$ & $88.2 \pm 40$ & $<0.001$ \\
\hline \multicolumn{4}{|l|}{ Imunosupresant } \\
\hline Steroid + cyclophosphamide & $29(85.3)$ & $65(39.4)$ & $<0.001$ \\
\hline Steroid & $5(14.7)$ & $100(60.6)$ & \\
\hline \multicolumn{4}{|l|}{ Age of onset NS (years) } \\
\hline$\leq 5$ & $16(47.1)$ & $81(49.1)$ & 0.426 \\
\hline$>5$ & $18(52.9)$ & $84(50.9)$ & \\
\hline \multicolumn{4}{|l|}{ Gender } \\
\hline Male & $20(58.8)$ & $134(81.2)$ & 0.004 \\
\hline Female & $14(41.2)$ & $31(18.8)$ & \\
\hline \multicolumn{4}{|l|}{ Nutritional atatus } \\
\hline Under nutrition & $9(26.5)$ & $11(6.7)$ & 0.002 \\
\hline Good nutrition & $25(73.5)$ & $154(93.3)$ & \\
\hline
\end{tabular}

In this study, age of NS onset higer in age above 5 years, predominanly male, with good nutritional status. The most common type of nephrotic syndrome is dominant teroid resistant nephrotic syndrome (SRNS). Risk factors for tuberculosis are listed in Table 1.

The result of multiple logistic regression multivariate analysis as listed in Table 2 demonstrated that the duration of steroids had the most influence factors of tuberculosis, patients with duration of steroids 175,5 days had 20,7 times risk for TB, patient with combination of steroids with cyclophosphamide had 3,2 times risk for TB, female sex patient had 2,5 times risk for TB, and under nutrition had 7,2 times risk for TB.

Table 2. Logistic Regression Analysis for Risk Factor of Tuberculosis in Nephrotic Syndrome

\begin{tabular}{lcc}
\hline Risk Factors & $\begin{array}{c}\text { Adjusted OR } \\
\text { (CI 95\%) }\end{array}$ & P Value \\
\hline $\begin{array}{l}\text { Duration of steroid (175.5 days) } \\
\text { Imunosupresant }\end{array}$ & $20.7(7.5-68.1)$ & $<0.001$ \\
(Steroid+cyclophosphamide) & $3.2(1.1-11.7)$ & 0.027 \\
Gender (Female) & $2.5(0.9-7.2)$ & 0.077 \\
Nutritional status (under nutrition) & $7.2(2.4-34.7)$ & 0.001 \\
\hline
\end{tabular}

\section{Discussion}

Patients with NS are in immunocompromised condition due to their own disease as well as to steroid and immunosuppressant therapy. [3] One of the highes incidence of infection in Indonesia is tuberculosis. [5] In this study we found 34 children with TB from 199 NS patients who came to RSHS as stated in medical record data for 5 years, the prevalence of tuberculosis in patients with NS in RSHS was $17 \%$, higher than previous study at RSCM by Tambunan which prevalence of TB in NS was $15 \%$. [9] Increased prevalence of TB in patients with NS was in line with increasing number of new TB cases around the world. [10]

In this study duration of steroid administration, combination steroid and cyclophosphamide, female gender and undernutrition were significant factors of tuberculosis in NS.

Side effects of steroid administration depend on steroid types, duration of administration and combination with other immunosuppressants. [11] Previous studies had shown that long-term steroid might increase the risk of infection. [12]

Administration of steroids 175,5 days (5,8 month) exposed patient to higher chance of TB occurrence. A previous study in India (1993) found that secondary TB infection occurred averagely within 2.2 years after diagnosis of NS. [10] Steroids work to suppress cell-mediated immunity through inhibition of genes coding IL-1, IL-2, IL3, IL-4, IL-5, IL-6, IL-8 and TNF- $\alpha$ cytokines. The produced cytokines can decrease the proliferation of $\mathrm{T}$ cells, as well as humoral immune system by causing B cells to secrete IL-2 and IL-2 receptors. [13]

The study showed that the duration of steroid administration had a greater role in the risk of TB. It was suspected that this result was related to the pathogenesis of TB. Naturally, Mycobacterium tuberculosis (Mtb) infection requires incubation period of 2-12 weeks until the formation of the primary complex. In most individuals 
with a well-functioning immune system, where they continue to live and stay for years in this complex, but do not manifest as TB disease. Decreased immunity as the result of steroids consumption for long periods of time causes these bacteria in the body to reactivated and cause symptoms of TB. [14]

Combination of steroids and cyclophosphamide was a risk factor of TB. Steroids and cyclophosphamides are immunosuppressants acting on $\mathrm{T}$ cells with different mechanisms of action. [13] The combination of both immunosuppressants causes inhibition of heavier $\mathrm{T}$ cells that leads to a decline in cellular immunity that is a major line of defense in Mtb infection [14]. Previous study in India found prevalence TB was similar in children who received steroid and those who received steroid and cyclophosphamide. [10]

Literature and previous studies stated that idiopathic NS and Minimal Change NS (MCNS) type were more common in female. In additional, type MCNS cases were usually not responsive for steroid theraphy and required other immunosuppresants that put females at higer risk of infection. [15] The authors suspected this reason as the answer to the higher $\mathrm{Tb}$ incidence among female patient. Malnutrition is a risk factor for tuberculosis, malnourished patients are in immunocompromise condition, facilitate occurrence of infection. Studies have shown that malnutrition (both micro- and macro-deficiency) increases the risk of TB because of an impaired immune response. [8]

Age less than 5 years is one of the TB risk factors as the result of imperfectly fuctioning immune system, but statistical calculations showed no significant difference between the two groups [8]. Non significant result was probably due to small sample of TB patient in this study.

This study has some limitations, the data were taken from medical records, some medical records had incomplete data so it must be excluded, no subject with positive bacteriologic tuberculosis test result. This study was conducted only at tertiary hospital, so it could not reflect the lower service level conditions.

\section{Conclussion}

The duration of steroid administration, combination of steroids and cyclophosphamide, female gender, under nutrition were risk factors for tuberculosis in NS. The duration of steroid administration has a greater role in the risk of TB, compared to other risk factors.

\section{Acknowledgements}

We thanked to Professor Dedi Rachmadi and Doctor Diah Asri for counseling of the study design and initial manuscript.

\section{References}

[1] Bagga A, Mantan M, Nephrotic syndrome in children, Indian J Med Res, India, 2005, 13-28.

[2] Niaudet $\mathrm{P}$, Boyer O, Idiopathic nephrotic syndrome in children: clinical aspect. In: Avner E, Harmon W, Niaudet P, Yoshikawa N (ed), Springer, Berlin, 2009, 667-702.

[3] Cohen E, Nephrotic syndrome, Medscape, 2016, 1-20.

[4] Latta K, Schnakenburg C, Ehrich J, A meta analysis of cytotoxic treatment for frequently relapsing nephrotic syndrome in children. Pediatr Nephrol, 2001; 16: 271-282.

[5] Direktorat Jenderal Pencegahan dan Pengendalian Penyakit, Petunjuk teknis manajemen dan tatalaksana TB pada anak, Kementerian Kesehatan Republik Indonesia, Jakarta: 2016.

[6] Onal CO, Kibaroglu E, Pulmonary tuberculosis caused by immunosuppresive treatment, J Clin Case Rep, USA, 2014, 4-7.

[7] Li S, Zhang M, Chen, An implication of relationship between tuberculosis and primary nephrotic syndrome, Int J Artif Organs and SAGE, China, 2015,178-83.

[8] Narasimhan P, James W, Raina M, Mathai D, Risk factor for tuberculosis, Hindawi, India, 2013, 1-11

[9] Tambunan T, Dewati A, madiyono B, Rahayoe N. Pulmonary tuberculosis in childhood nephrotic syndrome (A cross sectional study). Paediatr Indones, Indonesia, 2001, 106-10.

[10] Gulati S, Kher V, Gulati K, Arora P, Gujral R. Tuberculosis in childhood nephrotic syndrome in India. Pediatr Nephrol, India, 1997, 695-8.

[11] Liu D, Ahmet A, Ward L, Krishnamoorthy P, A practice guide to the monitoring and management of the complication of systemic corticosteroid therapy, AACI jounal, Canada,2013, 1-25.

[12] Youssef J, Novosad S, Winthrop K, Infection risk and safety of corticosteroid use. Rheum Dis Clin North Am 2017; 42: 1-4.

[13] Rather P, Channudhary H, Rathhee S, Immunosuppressant: A review, Theparmajourn, India, 2013, 90-92.

[14] Shi R, Sugawara I, Pathophysiology of tuberculosis, Tuberculosis current issues in diagnosis and management. Intech Open Science 2000: 127-139.

[15] Hogg R, Middleton J, Vehaskari M, Focal segmental glomerulosclerosis-epidemiology aspect in children and adults. Pediatr Nephrol, 2007; 22: 183-186 